\title{
0 processo de ensino e aprendizagem de Biologia em consonância com a educação do campo, sob a perspectiva da sustentabilidade
}

\section{Leandro Mendes Salustino}

Escola Estadual de Ensino Fundamental e Médio Campo Sementes e Mudas. Rodovia PB-004, S/№. Cruz do Espírito Santo-PB, Brasil (CEP 58337-000). Email: leandro-cruz@outlook.com.

Resumo. 0 objetivo da presente pesquisa foi aplicar alternativas pedagógicas voltada ao ensino e a aprendizagem de Biologia, em consonância com a Educação do Campo e sob a perspectiva da sustentabilidade, com os alunos do $1^{\mathrm{o}}$ ano do Ensino Médio da Escola Estadual de Ensino Fundamental e Médio Campo, Sementes e Mudas, Município de Cruz do Espírito Santo, Estado da Paraíba, Nordeste do Brasil. A pesquisa foi metodologicamente desenvolvida de forma multidisciplinar, a partir de uma abordagem qualitativa, buscando-se identificar algumas variáveis acerca do desenvolvimento de práticas pedagógicas que viessem a auxiliar o processo de ensino e aprendizagem na área disciplinar de Biologia. Realizaram-se visitas a produtores da agricultura familiar que estavam exercendo práticas agrícolas exitosas em suas propriedades. No decorrer das ações, os alunos tiveram a oportunidade de participar de uma palestra com uma técnica agrícola, sobre a agricultura familiar, participaram de atividades práticas, como a confecção de composteira doméstica, fizeram uma ação efetiva de cuidado com o meio ambiente ao realizarem a coleta de garrafas PET, cordão de rede, fio de cadeira, dentre outros materiais. Conclui-se que todas as atividades propostas fizeram com que os alunos desenvolvessem múltiplas habilidades relacionadas ao currículo das disciplinas envolvidas, quanto de aspectos relacionados a habilidades e atitudes socioemocionais e fortalecimento das relações interpessoais.

Palavras-chave: Ensino; Aprendizagem; Biologia; Educação do campo.

\footnotetext{
Abstract. The process of teaching and learning Biology in line with rural education, from the perspective of sustainability. The objective of the present research was to apply pedagogical alternatives focused on the teaching and learning of Biology, in line with the education of the field and from the perspective of sustainability with the students of the 1st year of high school of the Escola Estadual de Ensino Fundamental e Médio Campo, Sementes e Mudas, at Cruz do Espírito Santo, Paraíba State,
}

Recebido

$04 / 11 / 2019$

Aceito

$22 / 12 / 2019$

Publicado

$31 / 12 / 2019$

Acesso aberto

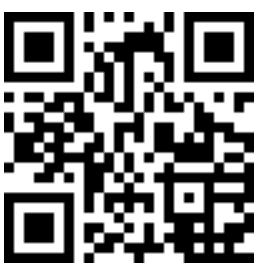

ORCID

(1) 0000-0002-3449-4446 Leandro Mendes Salustino 
Northeast Brazil. It was methodologically developed in a multidisciplinary way, which proceeded from a qualitative approach, seeking to identify some variables about the development of pedagogical practices that would assist in the teaching and learning process in the disciplinary area of Biology. Visits were made to family farmers who were doing successful farming on their farms. During the actions students had the opportunity to participate in a lecture with an agricultural technique on family farming. Participated in practical activities, such as the making of domestic composer. They took an effective action of caring for the environment by collecting PETES bottles, mesh cord, chair wire, among other materials. It is concluded that all the proposed activities led the students to develop multiple skills related to the curriculum of the subjects involved, as well as aspects related to skills and social and emotional attitudes and strengthening interpersonal relationships.

Keywords: Teaching; Learning; Biology; Field education.

\section{Introdução}

A Biologia se apresenta como uma ciência ampla e dinâmica que está em constante desenvolvimento. Desta maneira, o professor de Biologia deve se portar como um pesquisador, que além de buscar se atualizar no que cerne o ensino e a aprendizagem de Biologia deve avaliar constantemente as suas práticas pedagógicas e metodologias, proporcionando ao aluno a possibilidade de se tornar também pesquisador e produtor de conhecimento (Pedrancini et al., 2007).

Sob esta perspectiva é possível observar que nas últimas décadas vêm crescendo as iniciativas metodológicas que visam aproximar as teorias presentes nos livros e as aulas em sala com o contexto que os educandos e a comunidade escolar estão inseridos, ou seja, nesta busca para aliar a teoria à prática, é importante levar em consideração aspectos da realidade dos educandos, como por exemplo, os relacionados à condição cultural, social, econômica e ambiental (Krasilchik, 2004).

Portanto, é importante que os professores criem alternativas viáveis que auxiliem no ensino e na aprendizagem da Biologia em consonância com a educação do campo, tendo em vista a realidade ao qual a escola está inserida, bem como a sua identidade enquanto escola do campo. Neste sentido, apresentar uma aprendizagem que seja mais significativa onde os educandos tenham a possibilidade de se enxergarem como agentes de transformação de si e do seu entorno, requer ações pedagógicas que levem a autonomia e desenvolvimento dos educandos (Senicato e Cavassan, 2004).

Portanto, o presente artigo teve como objetivo aplicar alternativas pedagógicas voltada para o ensino e aprendizagem da biologia, em consonância com a educação do campo e sob a perspectiva da sustentabilidade com os alunos do $1^{\mathrm{o}}$ ano do ensino médio da Escola Estadual de Ensino Fundamental e Médio Campo Sementes e Mudas.

A escola citada está situada em uma comunidade rural denominada Campo sementes e Mudas, localizada no Município de Cruz do Espírito Santo-PB. 0 público atendido nesta instituição em sua maioria reside no campo, muitos sobrevivem do cultivo da agricultura, sendo de grande importância valorizar e regatar o desejo de está no campo na atualidade. Esta instituição educacional 
traz entre suas responsabilidades proporcionar ações que valorize o conhecimento dos alunos e os motive a valorizar suas práticas no cotidiano.

\section{Ensino de Biologia e a Educação Ambiental}

Conforme Borges e Lima (2007) a Biologia preocupa-se com o estudo sobre os seres vivos, sobre as características e a conduta dos organismos, bem como a origem de espécies e indivíduos e o modo como interagem no ambiente. Neste sentido, o aprendizado dos conteúdos curriculares da biologia deve possibilitar o entendimento da natureza na sua amplitude, tal qual pode se modificar e ser questionado, sendo preciso entender que a disciplina não tem respostas prontas e concluídas para tudo, o que a deixa aberta para uma série de debates.

Os temas relacionados à Biologia são relevantes para a compreensão dos fenômenos, pois produzem uma melhoria na qualidade de vida, de um lado, e um saudável relacionamento com o meio ambiente e condições de uma completa prática de cidadania. Inúmeras vezes os conteúdos curriculares não produzem definição, implicando na sua desvinculação do cotidiano, prejudicando o processo em que o aluno seja ator do seu aprendizado, isto por conta da falta de valorização dos conhecimentos preliminares, questionamentos e a falta de aulas que trabalhem a experiência de pesquisas (Sousa Sobrinho, 2009).

Deste modo:

É preciso superar o ensino de Ciências que tem metodologias centradas na decoreba de conteúdo, de repetição e de realização de experimentos em laboratórios que não prevêem a interação do aluno com objeto em estudo. Para a compreensão dos conhecimentos, os alunos precisam estabelecer relações entre o que aprenderam e a realidade, aprender a partir de seus conhecimentos prévios, nos questionamentos, experimentos e pesquisas associados à aula teórica (Portela, 2004, p. 30).

Sendo assim, tratar dos conteúdos de ciências, buscando-se a concepção dos processos e a reconstrução de um conteúdo escolar da referida área de extrema significância para estudante, tornando-se um modo de exercer, com responsabilidade, a função de professor educador. Isto complementaria o processo de ensinoaprendizagem, contribuindo positivamente tanto para o lado do professor quanto do aluno (Sousa Sobrinho, 2009).

Por sua vez, o ensino de Biologia tem como finalidade fazer compreender os conceitos fundamentais da disciplina, dando as reais capacidades para que os alunos tenha a capacidade de pensar de modo autônomo, adquirindo e avaliando informações, colocando-as em práticas nos seus conhecimentos na vida diária (Krasilchik, 2008).

No decorrer das aulas, os estudantes têm contato com o conteúdo teórico, aonde, muitas vezes, não conseguem estabelecer uma relação com ocasiões diárias ou práticas. Para evitar essas faltas de articulação é importante que os professores planejem e coloquem em prática junto com os alunos $o$ desenvolvimento de práticas de educação ambiental enquanto estratégia pedagógica para conscientizar dos enormes prejuízos que vem se impondo ao meio ambiente, como, por exemplo, "processos de degradação, assim como na construção de valores, conhecimentos, habilidades, atitudes e competências voltadas para a conservação do meio ambiente" (Krasilchik, 2008, p. 39).

Neste contexto, o aprendizado fica limitado as viáveis relações construídas pelos alunos por conta da sua vivência pessoal, apresentando reais condições para provocar conceitos científicos da área de Biologia para se tenha uma visão da sua aplicabilidade na realidade, mesmo que seja na sala de aula. 
Por sua vez, conforme Borges e Lima (2007), as aulas de campo provocam a participação do aluno, o que leva a melhorar seu rendimento escolar, pois viabiliza a exploração de conteúdos e conceitos capazes de complementar temas já trabalhados em sala de aula, ou estimula estudos para outras ocasiões. Sendo assim:

[...] o trabalho de consciência ambiental deve ser realizado por meio de professores que a possuem. Nesse contexto, a escola é o local ideal para promover a consciência ambiental, já que às disciplinas são os recursos didáticos colocados ao alcance dos alunos (CAVALIERI, 2002).

Consciência ambiente e educação do campo podem se complementar para formar cidadãos conscientes e livres, mediante práticas que vinculam conteúdos e assuntos da realidade diária. Assim ela organiza enquanto específica e diferenciada, construída para dar conta das necessidades dos estudantes das famílias trabalhadoras do campo. Porém, é notado que as escolas, não semente as do campo, vêm assumindo uma responsabilidade de transmissora de assuntos escolares gerais e tradicionais, com aulas expositivas sem uso de práticas pedagógicas, fazendo limitar os conteúdos à livros didáticos, tais quais corroboram com o uso de metodologias que encaminham a memorização e não o aprendizado, ou seja, uma metodologia mais centralizada no professor, fazendo com que os conteúdos fiquem longe da realidade dos alunos. Deste modo:

Fica evidente, a necessidade de se buscar novos métodos, que motivem os alunos a aprenderem e a compreenderem o significado do conhecimento para suas vidas. Os professores precisam encontrar novas possibilidades para um ensino de qualidade, como observações, atividades práticas contextualização dos conteúdos, temas geradores e projetos interdisciplinares que aproximam os conteúdos com a realidade dos alunos (Brito e Silva, 2015, p. 30).

No sentido colocado pela citação, pode-se dizer que a realidade vivida pelos alunos deve ser o ponto de partida para uma abordagem pedagógica, de cunho teórico, aonde viabilize $o$ desenvolvimento do pensamento reflexivo e do conhecimento científico.

Paulo Freire (2001) apresenta a educação problematizadora, que trata a realidade enquanto um processo inserido no próprio contexto educacional, tendo como base os processos de ensino\ aprendizagem pautados no diálogo, na reflexão e na criatividade. 0 autor se coloca contrário a educação como meio de opressão, aonde o aluno é percebido como sujeito social e educacional que nada sabe e o conhecimento é posto a todo custo pelo professor. Sendo assim:

[...] o diálogo deve começar na busca do conteúdo programático a ser trabalhado, qual poder ser construído a partir dos Temas Geradores, proposto a partir do universo do educando, identificados a partir da análise da realidade. A valorização dos temas geradores é baseada na compreensão das relações homem-mundo, não se encontra nos homens isolados de sua realidade (Gomes e Farias, 2009).

Assim, no desenvolvimento de temas geradores, pode-se entrecruzar a disciplina da Biologia com a realidade do campo, apontando que a mesma pode torna-se norteadora dos conteúdos da prática pedagógica postos em prática nas escolas do campo, gerando a reflexão dos conteúdos socialmente ajustados a realidade do alunado.

Além disso, ela pode auxiliar para formação e a prática docente atrelada ao campo das Ciências da Natureza, aonde a organização da prática educativa deverá levar em conta a relação entre a definição do Tema Gerador e a assimilação do 
conhecimento dos professores na direção de ações educativa.

Gomes e Farias (2011) ressalta que a efetivação dos temas geradores acontece entre educador e educando mediante o próprio ato de pesquisa da realidade, aonde se estuda e analisa de modo crítico as suas contradições e, ao mesmo tempo, a dinâmica histórica que lhe formou.

Para Torres (2014), a educação fundamentada na realidade dos indivíduos, responsabiliza-se pela função básica no processo de libertação dos homens e da sociedade. Isto é importante para entender a dinâmica social e educacional da escola do campo, tal qual abarca alunos e professores que precisam fazer um processo educacional capaz de dar as primeiras ações para o objetivo libertador. Porém:

[...] destaca-se a dificuldade na escola em trabalhar com os Temas Geradores, devido a necessidade de preparo dos educadores com relação a leitura, ao estudo e ao posicionamento critico, assim como também a dificuldade dos professores em romper com os moldes da educação bancária descrita por Paulo Freire (Santos, 2007, p. 45).

É notável que a educação do campo tenha certas barreiras a superar, desde a dimensão pedagógica até a estrutural. E um dos elementos mais importante deve-se ao fato da parte docente se alinhar com as orientações de uma educação do campo que retrate responsavelmente 0 processo de educação libertadora, mas sempre dando os contornos de escolarização, mediante o seu conteúdo curricular.

Neste contexto pedagógico citado, o ensino de biologia deve ser transformado no sentido de superar "práticas que supervalorizam conceitos, memorização de nomes e processos biológicos, métodos conservadores, quais fragmentam o conhecimento dificultando o aprofundamento dos conteúdos" (Gomes e Farias, 2011).

Deste modo, a prática e a formação dos professores são relevantes, pois se responsabilizam dar orientação aos processos educacionais mais eficientes, produzindo a possibilidade de transformações e construção das relações de ensino/aprendizagem que prezem por uma educação que tanto tenha o caráter libertador, mais que trabalhe um processo formativo eficiente e responsável (Ribeiro, 2013, p. 38).

Inúmeros professores concluem os cursos de licenciatura e de formação continuada sem ter a menor noção do modo de vida camponês, sendo que o padrão de vida urbana sobressai nas relações sociais e econômicas brasileiras, o que não permite valorizar a educação do campo. É preciso apreciar a transmissão de conhecimentos na formação de professores, que os dêem condição de valorizar o campo e a cultura dos povos do campo (Ribeiro, 2013).

Construir, através de meios didáticos e pedagógicos, um perfil de formação do professor que dar condições para estar fortalecido por um entendimento da realidade do campo, na qual está incluso e prepare-o para intervir e ser responsável com a luta e objetivos educacionais destes povos, resultando numa educação mais ajustada a realidade do público citado e, com isso, trará mais resultados na área.

Para Pessoa (2007, p. 12):

O movimento da Educação do Campo compreende que a Escola do Campo deva ser uma aliada dos sujeitos sociais em luta para poderem continuar existindo enquanto camponeses e para continuar garantindo a reprodução material de suas vidas a partir do trabalho na terra.

Para tanto, é imperativo que a formação dos educadores que estão sendo preparados para lecionar nestas escolas considere, antes de tudo, que a existência e a permanência (tanto destas 
escolas, quanto destes sujeitos) percorrem, necessariamente, por uma orientação que se executa através dos desdobramentos da "luta de classes, do resultado das forças em disputa na construção dos distintos projetos de campo na sociedade brasileira" (Molina, 2014, p. 39).

A Educação do Campo tem como finalidade, segundo Pessoa (2007) construir uma formação que dê valor ao campo e o camponês, trilhando o contra movimento do projeto econômico que se expressa numa educação metódica, que está em profunda desconexão social e política com a realidade.

Neste sentido, o processo de Educação do Campo surge enquanto uma crítica à realidade da educação brasileira, principalmente ao contexto educacional do povo brasileiro que trabalha e vive no/do campo, uma vez que a educação no meio rural sempre foi colocada na marginalidade das políticas públicas (Ribeiro, 2013).

Portanto, a escola do campo vem com o propósito de se produzir o conhecimento através da cultura e do modo de vida dos camponeses, cabendo ao professor de biologia buscar adequarse a tal finalidade. Sendo assim, o ensino de biologia deve estar organizado e alinhado com uma perspectiva que preze realmente pelo contexto da comunidade.

A partir dessa perspectiva, as escolas de educação do campo devem ter suas propostas orientadas em um ensino que atenda as particularidades e valorize a identidade do povo campesino, o que implica que os professores de biologia realizem atividades pedagógicas que articulem a demanda curricular com a dinâmica social local.

\section{Materiais e métodos}

0 artigo em questão foi metodologicamente dividido em duas partes, aonde primeiramente se trabalhou com análise de literatura. E na segunda parte, foi desenvolvida de forma multidisciplinar, uma abordagem investigativa qualitativa, buscando-se colocar em prática ações pedagógicas que viesse auxiliar no processo de ensino e aprendizagem na área disciplinar de biologia, considerando o desenvolvimento das capacidades dos alunos com relação à aprendizagem de conceitos, de procedimentos e de atitudes relacionadas à respectiva disciplina.

A partir da realização de uma abordagem qualitativa que priorizou âmbito das experiências de ensino, buscou-se colocar em prática uma aprendizagem dos assuntos curriculares biologia em consonância com a educação do campo sob a perspectiva da sustentabilidade, tais quais foram expostos através de atividades capazes de dar uma maior compreensão aos alunos acerca de temas que se relacionam com o currículo de Biologia para o Ensino Médio.

Deste modo, este foi um trabalho que não se preocupou restritamente com a representatividade quantitativa, mas sim com o aprofundamento do ato de fazer compreender, explicar os porquês das coisas e propor experiências pedagógicas para o alunado do $1^{0}$ ano médio da instituição educacional em questão.

0 material apresentado na próxima seção é o resumo sistematizado das experiências didáticas e pedagógicas de uma educação que se direciona para as atividades do campo, do meio rural. Apresentá-las, implica em demonstrar a relação sujeito aprendiz e o meio social no qual eles estão cotidianamente inseridos, haja vista que são residentes em áreas rurais. Trazer esse conjunto de relatos de experiências é expor uma série de atividades que inter-relaciona $o$ currículo de biologia com as vivências na própria cotidianidade dos alunos e na qual a escola está inserida.

Os procedimentos metodológicos utilizados foram diversificados, aonde todos se pautaram na aplicação de atividades com o alunado da série citada. De acordo com público ao qual se destinou, foram desenvolvidas atividades 
que deram condições para fazer um trabalho aonde observássemos o início, meio e fim do mesmo, dando reais condições para aplicar, entender 0 processo educacional no qual estávamos inserindo os alunos e obter resultados que se traduziram na descrição das experiências vividas por eles.

Portanto, foram realizadas atividades práticas com $\mathrm{o}$ fito de promover ações para que os alunos obtivessem um aprendizado que desse subsídios para que gerassem a própria consciência e, também, que pudessem projetar nos mesmos valores morais capazes de fazê-los mais responsáveis com a sustentabilidade.

Trabalhou-se com práticas pedagógicas que viessem ajudar o alunado na compreensão da temática da sustentabilidade ambiental, articulada com o processo de ensino e aprendizagem, aonde mediante $\mathrm{o}$ desdobramento das ações, tem-se certo avanço na compreensão da necessidade de manter um meio ambiente equilibrado e que tenha condições de existir para as próximas gerações.

\section{Resultados e discussão}

A primeira ação desenvolvida, em 4 de maio de 2018, foi a apresentação do projeto, aonde foi exibido vídeo e, também, teve explanação oral com ênfase para a educação do campo. Sendo assim, iniciou-se a referida ação do projeto de intervenção pedagógica da disciplina de Biologia com a turma de alunos do $1^{\circ}$ ano do ensino médio da Escola Campo Sementes e Mudas.

Ornamentou-se o centro do círculo com objetos que remetiam a identidade da pessoa do campo, bem como a um sentimento de orgulho das raízes do público citado e das vitórias alcançadas ao longo das histórias de lutas por dignidade e justiça social no Brasil, no Nordeste e na Paraíba.

Colocou-se objetos utilizados pelo homem do campo, como o chapéu de palha a enxada, utensílios feito de barro, frutos da terra e a bandeira do Brasil. Além disso, foram expostas imagens que remetiam às atividades do campo, coladas com fitas nos birôs. Tudo isso para criar um ambiente propício para assimilação da proposta daquela ação, que era de grande importância para os alunos começarem a tomar consciência do espaço camponês.

Em seguida trabalhou-se a música "Educação do campo é direito e não esmola". Ao termino desta, fez-se junto aos alunos uma reflexão sobre a mensagem principal da música. Obtevese resultado satisfatório, uma vez que foram apresentadas pelo alunado importantes contribuições em relação ao entendimento acerca dos direitos enquanto alunos residentes no campo e educandos de uma escola do campo. Por exemplo, falaram que não se sentiam inferiorizados e que não permitiriam que os descriminassem pelo fato de residir em zona rural e nem por estudar em uma escola do campo.

Expôs-se para os alunos que não se pretendia apenas estimulá-los a permanecer no campo ou a desenvolver atividades agrícolas, mas que a intenção seria de mostrar uma alternativa e perspectiva de futuro, dentre as várias outras que eles poderiam seguir. Aliada a esta alternativa, pretendeu-se fortalecer nos alunos a identidade e o orgulho enquanto pessoa do campo, bem como oferecer um ensino de Biologia mais dinamizado e prazeroso.

Para isso, levou-se em consideração a realidade ao qual eles estão inseridos, os elementos do cotidiano dos alunos, os espaços disponíveis para realizar as aulas de campo e a associação dessas aulas aos conteúdos de Biologia, sobretudo, sobretudo aos referentes à sustentabilidade ambiental.

A segunda ação consistiu na realização de uma visita de reconhecimento dos possíveis espaços que poderíamos utilizar para desenvolver de maneira satisfatória as atividades pedagógicas, concernentes à 
educação do campo e das demais vertentes existentes que de modo interdisciplinar se relacionam com a presente abordagem. A mesma foi realizada no dia 18/05/2018.

Desse modo, a turma foi orientada a ter uma percepção mais atenta em relação aos espaços disponíveis, bem como ao que poderia ser realizado nos espaços ociosos. No decorrer do percurso foi possível perceber o entusiasmo e a vontade de realizar dos alunos para descobrir, projetar e realizar as práticas propostas para estes espaços.

A escola Campo Sementes e Mudas fica situada em um ambiente natural rico em potencialidades agrícolas, como, por exemplo, solo fértil e recursos hídricos em abundância. Além disso, é habitada por moradores que tem muita experiência no trato com a terra. Sendo assim, todas essas potencialidades da comunidade foram sendo passadas para os alunos que ouviam atentamente. Durante a visita, os alunos também conseguiram identificar o cultivo de várias culturas, como, por exemplo, batata doce, macaxeira, milho, cana de açúcar, além da criação de peixes em tanque, criação de galinhas.

Ao avaliar a execução desta atividade foi possível perceber que já começou a acontecer uma conscientização dos alunos em relação às potencialidades do local em que eles são residentes, sendo que alguns comentaram que convivem com aquele ambiente cotidianamente e ainda não tinha observado as riquezas dos detalhes e a diversidade de culturas que já existem naquela localidade.

Sendo assim, o meio rural e as atividades agrícolas foram e continuam sendo a base para o sustento financeiro de dezenas de famílias. Com isso é inevitável refletir sobre o fortalecimento das raízes da pessoa do campo, que já começa a sair do estereótipo de pessoa de baixo índice socioeconômico, com baixo grau de escolaridade.
Este estereótipo deve ser superado, passando-se a reconhecer as pessoas residentes em áreas rurais como indivíduos com diversas capacidades, que pode continuar explorando suas terras de maneira sustentável e com uma baixa agressão aos recursos naturais, que pode continuar estudando, aplicando o seu aprendizado mediante o uso das técnicas na sua propriedade.

A terceira ação, dia 01-06-2018, tratou da visita a produtores da agricultura familiar que estavam exercendo práticas agrícolas exitosas. Em síntese a presente ação consistiu em conhecer práticas agrícolas de significativo destaque que tenham características da agricultura familiar e que desempenham suas atividades aliadas com a sustentabilidade ambiental, de modo que a exploração dos recursos naturais seja feita de uma maneira que os impactos ambientais sejam minimizados.

Antes de sair para as visitas, os alunos e alunas foram orientados em relação aos objetivos que pretendíamos alcançar com o desenvolvimento da ação. Foram, também, bem incentivados a criarem coletivamente um questionário para fazerem breves entrevistas com os produtores, ao mesmo tempo que conheciam os espaços de produção. 0 questionário foi elaborado com as seguintes questões:

1- Como e há quantos anos surgiu a ideia do negócio (produção agrícola)?

2- Houve dificuldade para a aquisição da diversidade de plantas?

3- Tiveram alguma dificuldade com o manejo da produção?

4- A produção é lucrativa do ponto de vista financeiro?

5- Quantas pessoas ajudam na produção?

Após serem dadas todas as orientações, concluirmos o questionário e terminarmos o roteiro da ação. Saímos para fazermos a primeira visita, que foi na propriedade da senhora Eva Riama de 
Oliveira, residente na comunidade Campo Sementes e Mudas, trabalha junto com os seus familiares na produção de mudas de plantas ornamentais e de frutas, com a utilização de algumas técnicas agrícolas com a enxertia e a compostagem.

Ao chegar à propriedade da senhora Eva, fomos muito bem recebidos. Além disso, foram enfatizados novamente os objetivos daquela ação e os motivos da nossa visita a sua propriedade. Então, a entrevistada de maneira solícita e espontânea começou a nos mostrar cada canto da sua área de produção e todas as técnicas que se utilizava para manter a produção.

Por exemplo, a mesma mostrou as técnicas de irrigação, onde ela nos explicou que possui um poço artesiano próprio e que água utilizada para a irrigação é bombeada desse poço até próximo às plantas. Comentou, ainda, que uma parte da água é armazenada em recipientes, onde eles fazem a irrigação com a mangueira em alguns pontos e manualmente realizam a irrigação em outros espaços da propriedade para evitar o desperdício de água, o que implica na redução de energia utilizada para fazer a bomba funcionar.

Ela explicou que a maioria dos vasos utilizados para colocar as plantas são reutilizados: baldes, bacias, recipientes de tintas, de manteiga, dentre outros. Outro destaque feito pela entrevistada diz respeito a forma como é produzida a compostagem na sua propriedade, o que foi muito proveitoso para ampliar a conscientização ambiental do alunado presente.

De acordo com a sua explicação, trata-se de uma técnica muito simples que consiste em juntar matéria orgânica morta, como folhas e galhos de árvores, e esperar a ação natural dos microrganismos, como fungos e bactérias, que são responsáveis pela degradação da matéria orgânica, transformando-as em um material riquíssimos em nutrientes. Explicou, também, que $o$ processo de compostagem é necessário em dados momentos para revirar a matéria orgânica e molhar, caso o esteja em um período seco do ano.

Em seguida a senhora Eva nos explicou como é feita a enxertia das plantas, tratando-se de outro processo relativamente simples que é utilizado para acelerar o desenvolvimento da planta. Portanto, essa enxertia é considerada uma técnica de melhoramento genético que consiste em implantar parte de uma planta viva por meio do enxerto em outra da mesma ou de diferente espécie.

Após as ricas explicações obtidas através da entrevista com esta agricultora, pedimos que respondesse ao questionário. Fez-se a primeira pergunta do questionário (Como e há quantos anos surgiu a ideia do negócio/produção agrícola?). Ela falou que a ideia surgiu há 5 anos, de maneira bem natural, sendo que ela sempre gostou de cultivar plantas ornamentais para si própria como uma forma recreativa. Porém, a diversidade de plantas cresceram a ponto de ter excedente para comercialização e que a parte da participação do filho e do marido na produção e comercialização também foi ocorrendo naturalmente.

Quanto à segunda questão do questionário (Houve dificuldade para a aquisição da diversidade de plantas?), respondeu que a diversidade de plantas foi surgindo naturalmente, na medida em que as atividades de comercialização também estavam se desenvolvendo. Em relação à terceira pergunta (Tiveram alguma dificuldade com o manejo da produção?), a mesma relatou que não teve dificuldades no manejo da produção, pois já possuía experiência e, também, os recursos necessários para manter a produção, como, por exemplo, mão de obra e água para fazer a irrigação.

Em relação à quarta pergunta $(\mathrm{A}$ produção é lucrativa do ponto de vista financeiro?), a entrevistada respondeu que exercem outras atividades profissionais, mas que se optassem por aumentar a produção, dedicando-se 
exclusivamente ao trabalho na propriedade agrícola, conseguiria adquirir todo o sustento financeiro da família a partir da produção. Afirmou ainda que atualmente a produção oferece um rendimento financeiro que faz toda a diferença na renda da família.

Quanto à quinta pergunta (Quantas pessoas ajudam na produção?), afirmou que atualmente trabalham três pessoas na produção agrícola: ela o marido e o filho. Mesmo sendo três pessoas, dá para atender ao que se precisa para produzir e comercializar. Isto mostra que a sua propriedade tem fortes marcas de uma agricultura de base familiar, o que é positivo.

Em continuação a terceira ação do projeto, visitou-se a propriedade agrícola do senhor Luiz Sebastião da Silva, também residente na comunidade rural Campo Sementes e Mudas. Ao chegar com os alunos em sua propriedade, ele nos recebeu de maneira muito carinhosa e amigável, colocandose à disposição para mostrar todos os espaços da sua área de produção agrícola, bem como para tirar todas as dúvidas inerentes às atividades desenvolvidas por ele por seus familiares naquele espaço de produção agrícola.

Fomos conduzidos pelo mesmo para conhecer cada espaço da sua área de produção agrícola. Ao longo do percurso, ele falou do tempo estimado de cada cultura; do plantio até a colheita; da diversidade de alimentos que cultiva, como, por exemplo, tomates, couve, alface, coentro, feijão, jerimum, macaxeira, batata doce, amendoim, banana, coco, manga, girassol, dentre outros.

Depois nos reunimos para fazer uma breve entrevista. Ele começou falando que é natural do estado de Pernambuco. Além do mais, expôs que começou a trabalhar na agricultura muito cedo, por volta dos 15 anos de idade, e que atualmente faz 55 anos que ele trabalha na agricultura. Os alunos indagaram se ele gosta do que faz. Por sua vez, o entrevistado respondeu que "ama" e que não consegue ficar distante 
do trabalho com a terra, uma vez que esta atividade é o que o faz viver. Ressaltou ainda que quando precisa ficar distante do trabalho, sente-se doente.

Continuamos a entrevista com as questões que tínhamos elaborado coletivamente na sala de aula. Em relação à primeira pergunta (Como e há quantos anos surgiu a ideia do negócio (produção agrícola)?), ele respondeu que a ideia de trabalhar com a agricultura sempre fez parte da vida dele. No entanto, ele estava explorando aquele espaço aproximadamente há três anos, pelo fato do terreno dele ser relativamente grande, permitindo fazer uma rotação de cultura, aonde produz em determinada área do terreno durante certo período com a troca da área de cultivo para que o terreno possa se recuperar.

Em relação à segunda questão (Houve dificuldade para a aquisição da diversidade de plantas?), ele nos explicou que não teve dificuldades para adquirir a diversidade de cultura que possui atualmente, pois produz a maioria das mudas em sua propriedade. Ressaltou ainda que quando não consegue produzir, ele compra sem maiores dificuldades, ou adquire com os proprietários vizinhos.

Sobre a terceira questão (Tiveram alguma dificuldade com o manejo da produção?), relatou que não teve dificuldade no manejo, pois já possui bastante experiência na produção agrícola, sendo que trabalha na área desde a sua adolescência. Dando uma maturidade de trabalho que surte efeito positivo no desenvolvimento de suas atividades agrícolas.

Em relação à quarta pergunta (A produção é lucrativa do ponto de vista financeiro?), o entrevistado afirmou que o retorno financeiro é relativamente bom, isto pelo fato da produção ser realizada com a ajuda dos familiares e, também, por conta do escoamento da maior parte da produção ser feito na própria comunidade.

Referente à quinta pergunta (Quantas pessoas ajudam na produção?), o agricultor que entrevistamos respondeu que além dele ainda trabalha na produção agrícola mais um neto. Porém, quando precisa, chama mais duas pessoas da família para ajudar, haja vista que tem período que se faz necessário ter mais pessoas para dar conta da demanda a ser comercializada.

Através de avaliação com a turma e os demais professores presentes, consideramos que a realização desta atividade ocorreu de maneira bastante positiva e que os objetivos almejados foram amplamente alcançados, pois houve por parte de todos os envolvidos uma cooperação mútua e bastante empenho.

Pode-se destacar também que foi positiva a atividade por conta dos alunos terem se mostrados receptivos em relação a atividade proposta e por terem a oportunidade de perceber que nas atividades agrícolas não existem apenas histórias de fracasso, mas que existem exemplos de história bem sucedidas, onde famílias que apesarem de possuir uma área pequena para o cultivo, conseguem obter o sustento de suas famílias.

$\mathrm{Na}$ terceira ação pedagógica, $03 / 08 / 2018$, realizou-se uma palestra com representantes da Emater (mais precisamente com técnicas agrícolas) sobre a agricultura familiar. A referida ação aconteceu na sala de aula do primeiro ano da Escola Campo Sementes e Mudas. A execução desta ação foi possível graças a pareceria existente entre a escola Campo Sementes e Mudas e a ACRF (Associação Centro Rural de Formação), na qual as respectivas profissionais desenvolveram atividades técnicas e pedagógicas com crianças que possuem necessidades especiais.

As técnicas que vieram palestrar deram ênfase para o fato de também serem residentes em áreas rurais $\mathrm{e}$ possuírem uma ligação muito forte com a respectiva área, identificando-se, inclusive, como pessoas do campo, deixando-os mais próximos da realidade do alunado que assistia a atividade. 
Deste modo, as pessoas responsáveis pela palestra começaram esclarecendo o que é a agricultura familiar e quais os critérios utilizados para que as famílias possam ser consideradas como membros ativos da agricultura familiar. Por exemplo, o desenvolvimento de atividades econômicas no meio rural, que se enquadram (segundo dados apresentados por elas) em quatro módulos fiscais e que utilize predominantemente mão de obra da própria família nas atividades econômicas de propriedades, fazendo com que a maior parte da renda seja advinda das atividades agropecuárias desenvolvidas no meio rural.

Elas ainda destacaram, de acordo com dados do IBGE, a importância da agricultura familiar para a produção de alimentos no Brasil e quais são os principais programas de incentivo para a agricultura familiar. Argumentaram ainda os principais desafios enfrentados pelos agricultores da agricultura familiar, como por exemplo, o da competitividade com o agronegócio, que é dotado de maquinários e grandes extensões de terras.

Mais um desafio citado foi o da logística para o escoamento da produção, sendo que como muitos agricultores não possuem transporte para levar os produtos agrícolas até o consumidor final, leva-os a vender seus produtos por um preço muito inferior ao de valor de mercado ao atravessador, comprando a mercadoria por um preço baixíssimo e revendendo pelo dobro do valor pago que comprou do agricultor.

Outro ponto importante abordado pelas palestrantes foi o do protagonismo juvenil no meio rural, explicitando que se os jovens possuírem um olhar sensível as potencialidades existentes no campo, eles conseguem gerar renda dentro da sua própria área de cultivo, sem haver, portanto, a necessidade de se deslocar até a cidade em buscar de um trabalho ao qual não se identifica.
A quarta atividade foi a confecção da composteira doméstica, no 17/08/208. A presente ação alinhou-se ao eixo temático do projeto que aborda o viés da sustentabilidade, levando em consideração que é tão urgente pensar e colocar em práticas ideias que supram as necessidades humanas, sem comprometer os recursos naturais, nem causando risco às futuras gerações.

Com a prática da sustentabilidade, respeita-se também o meio ambiente e a biodiversidade, ofertando subsídios para que os públicos alvos desta ação formem uma consciência crítica e que se tornem agentes de transformação do seu entorno, sobretudo das localidades que residem (Freitas, 2011).

Por sua vez, a compostagem é um processo biológico de valorização da matéria orgânica, podendo ser ela de origem urbana, doméstica, industrial, agrícola ou florestal. Trata-se de um processo natural em que a matéria orgânica sofre degradação por microrganismos, podendo ser considerada como uma reciclagem do lixo orgânico, já que a matéria orgânica volta ao ciclo.

Optou-se por utilizar o processo que é mais comum em residências: o da vermicompostagem. Nele é colocado um recipiente com terra e minhoca para transformar resíduos orgânicos em adubos, sendo um processo bastante higiênico e que dependem de fatores simples, como, por exemplo, umidade, temperatura e aeração.

Para a construção da composteira doméstica foi utilizado três baldes de plástico com tampa e com capacidade de armazenamento de vinte litros, uma furadeira com broca de três milímetros para fazer os furos nos baldes e nas tampas. Ao concluir a composteira, colocou-se um $1 / 4$ de terra no balde de cima, em seguida foi colocado alguns resíduos orgânicos sobre a terra, cobrindo-o com o dobro de matéria seca, neste caso nós utilizamos folhas secas de árvores. 
A execução da presente atividade demonstrou de maneira prática e prazerosa, mostrando que é possível com medidas simples e de baixo custo promover uma consciência ambiental e sustentável, de modo que os próprios alunos pudessem se tornar agentes multiplicadores dessas e de outras ações em suas residências e na sociedade.

Na quinta atividade foi realizada a visita técnica à Escola Estadual de Ensino Fundamental e Médio Campo Sementes e Mudas, a qual se deu no dia 23 de agosto de 2018. A respectiva visita foi feita por professores finlandeses através do intermédio da SEE (Secretaria de Estado da Educação).

A visita dos professores se deu como uma continuação do projeto gira mundo Finlândia. Possibilitou-se aos envolvidos a troca de experiências, aonde os professores finlandeses tiveram a oportunidade de conhecer um pouco sobre como é desenvolvida a educação do campo na Paraíba.

Participou da visita um total de oito professores de duas instituições de ensino da Finlândia, os quais são parceiros da Secretaria de Estado da Educação da Paraíba, para o desenvolvimento do Programa Gira Mundo Finlândia, respectivamente, Häme University of Applied Sciences (HAMK), sediada em Hämeenlinna, e Tampere Universisty of Applied Sciences (TAMK), sediada em Tampere, ambas na Finlândia.

No decorrer da visita foram apresentados ao grupo de finlandeses, os principais projetos desenvolvidos pela escola Campo Sementes e Mudas, especialmente aqueles ligados diretamente ao contexto de educação do campo. Enfatizou-se, também, que o projeto político pedagógico que serviu para nortear as atividades pedagógicas inerentes à educação do campo foi primordial para a permanência dos alunos na escola, já que os alunos possuem uma identidade muito forte enquanto pessoas do campo, ou seja, as atividades desenvolvidas de acordo com o contexto dos alunos serviu para dar mais sentidos aos conteúdos estudados, diminuindo desta gradativamente a evasão escolar.

Outro ponto forte da visita foi a apresentação do nosso espaço integrado de conhecimento ao ar livre, o qual é conhecido por sala verde, onde se desenvolveu as atividades de horticultura e também atividades pedagógicas interdisciplinares.

Os professores finlandeses relataram, com o auxílio das tradutoras, grande apreço pelas práticas pedagógicas realizadas, aonde conseguiram ter uma dimensão da realidade brasileira e consequentemente dos alunos envolvidos no projeto gira mundo. Os professores afirmaram também que conseguiram identificar nas nessas práticas pedagógicas ações efetivas em relação a tecnologias sociais, além do incentivo ao empreendedorismo e a sustentabilidade, aplicadas ao contexto de educação do campo.

Os professores finlandeses presentes na referida atividade foram, vinculados a Tampere Universisty of Applied Sciences (TAMK) foram JuhaLahtinen, Carita Prokki, Hanna Saraketo. Já os docentes da Häme University of Applied Sciences (HAMK) foram Irma Kunnari, Marja Susanna, Seija Kultanen.

Por fim, fez-se uma entrevista com a equipe de assessoria de comunicação da Secretaria de Estado da Educação da Paraíba. Devido à forte vocação e as práticas pedagógicas voltadas para a educação do Campo, a escola Campo Sementes e Mudas foi contatada pela equipe de assessoria desta secretaria para a realização de uma entrevista sobre as práticas pedagógicas em educação do campo.

A sexta atividade realizada com o alunado do $1^{\mathrm{o}}$ médio da Escola E. E. F. M. Campos Sementes e Mudas foi a coleta de garrafa PET, fio de cadeira e cano de Pvc. Esta ação aconteceu no dia 14/09/2018 e consistiu na coleta de resíduos plásticos específicos, tal qual foi 
desenvolvida pelos alunos como uma extensão das ações executadas.

A proposta da presente ação foi de sensibilizar os alunos em relação à necessidade de adquirir uma postura de conservação do meio ambiente, tomando como base os princípios da sustentabilidade, tendo em vista que é necessário consumir de maneira equilibrada para que as próximas gerações não sejam afetadas e possam também usufruir de um ambiente sadio e rico em biodiversidade.

A respectiva atividade pedagógica foi pensada de maneira integrada $e$ contextualizada, de modo que uma ação servisse de base para a realização da ação seguinte. Desta maneira pensou-se na execução da mesma vislumbrando a execução da próxima atividade, que utilizou os materiais coletados para confeccionar um irrigador subterrâneo, que também agregasse os princípios da sustentabilidade.

Os alunos se empenharam na execução desta ação e conseguiram coletar todos os materiais solicitados, sendo eles: garrafa PET, fio plástico utilizado para cobrir cadeiras de balanços, e cano de Pvc. Considera-se que a presente ação conseguiu atingir os objetivos propostos, uma vez que houve dedicação por parte dos alunos para a execução da atividade.

É importante, também, ressaltar que já são perceptíveis a compreensão dos alunos em relação à sustentabilidade e a preservação do meio ambiente, o que mostra que outros tipos de atividades pedagógicas interdisciplinares mais alinhadas à realidade surtem efeitos positivos sobre o alunado que o pratica.

Quanto à sétima atividade, produziu-se um irrigador subterrâneo de baixo custo e com materiais alternativos, servindo para uso num canteiro experimental na horta orgânica da respectiva escola. Esta ação foi realizada no dia 28/09/2018, pelos alunos do $1^{\text {o }}$ ano do ensino médio, com supervisão do professor do IFPB, Francisco Fechine. Esta etapa foi realizada na sala de aula integrada ao ar livre nas dependências da própria, com materiais que foram previamente solicitados aos alunos.

Cabe ressaltar que a parceria da escola Campo Sementes e Mudas com o LETS (Laboratório Educacional de Tecnologias Sociais), por intermédio da SEE (Secretaria de Estado da Educação) foi viável o recebimento de um Kit fotovoltaico móvel e um tanque confeccionado de ferro e cimento, que está atualmente sendo utilizado para a criação de tilápias e para o armazenamento de água para fazer a irrigação da horticultura da escola.

Os resíduos provenientes da criação das tilápias é rico em nutrientes e é justamente esta água fertilizada que foi utilizada para fazer a irrigação do canteiro subterrâneo. Este tipo de irrigação possuiu diversas vantagens, entre elas estão: a economia de água, chegando acerca de $80 \%$ de economia, pois evita a evaporação excessiva de água já que a água vai diretamente para a raiz da planta e fica sob uma cobertura de terra. Por sua vez, outra vantagem importante diz respeito a facilidade no manejo, já que para fazer a irrigação bastou apenas abrir o registro de água.

A oitava ação pedagógica foi a entrevista realizada no dia 03/10/2018 na sala de aula integrada ao ar livre (horta orgânica) da Escola Estadual de Ensino Fundamental e Médio Campos, Sementes e Mudas. Na ocasião foi ouvida a gestora Edineuza de Oliveira Araújo, a qual abordou os desafios enfrentados pela escola, bem como a superação que está sendo a cada dia fortalecida pelas práticas de Educação do Campo, que toma como base a realidade local e o contexto ao qual os alunos estão inseridos.

Também foram entrevistados alguns alunos e alunas, que falaram da experiência de estudar em uma escola que trabalha a educação do campo como parte integrante do currículo, mostrando a satisfação do corpo discente, mais precisamente do $1^{\circ}$ ano médio, com as 
atividades pedagógicas desta instituição de ensino.

Na ocasião da inscrição no Projeto Mestres da Educação 2018, promovido pela Secretaria de Educação do Estado da Paraíba, tanto o autor detse artigo, quanto a professora Rejane do Nascimento Gomes Paiva foram entrevistados, uma vez que seus projetos abordam a educação do campo. $\mathrm{Na}$ entrevista foram citadas as principais motivações para colocar o eixo temático educação em nossos currículos, bem como sobre a importância de utilizar o espaço da horta orgânica como extensão da sala de aula convencional. A entrevista foi veiculada no jornal A União, do dia 5 de outubro de 2018, deixando os professores satisfeitos e com a sensação de que estão no caminho certo para alcançar uma educação de qualidade que leva a sério a realidade social e o contexto aos quais os alunos estão inseridos.

\section{Considerações finais}

0 presente artigo empreendeu um conjunto de relatos de experiências que expressaram a relação entre a teoria e a prática referente ao processo de ensino e aprendizagem da biologia em consonância com a educação do campo, sob a perspectiva da sustentabilidade. Deste modo, permitiu-se construir e apresentar um material inédito para e sobre a realidade da Escola Estadual de Ensino Fundamental e Médio Campos, Sementes e Mudas.

0 objetivo proposto foi devidamente atingido, uma vez que se conseguiu aplicar alternativas pedagógicas voltadas para o ensino e aprendizagem da Biologia, em consonância com a educação do campo e sob a perspectiva da sustentabilidade com os alunos do $1^{\underline{o}}$ ano do ensino da escola citada acima, de modo que os alunos vivenciassem a cotidianidade de alguns agricultores e de espaços agrícolas na Comunidade Campos Sementes e Mudas.
Portanto, o ensino de Biologia e a educação ambiental numa perspectiva da sustentabilidade permitiram problematizar questões de cunho teórico sobre aquilo que está posto referente ao ensino tradicional e $o$ que pode ser transformado no processo educacional, sobretudo na perspectiva de construir um ensino de biologia mais crítico e ajustado a realidade social, política e cultural do país, começando pela comunidade rural onde está situada a referida escola.

Quanto aos resultados e discussão, pôde-se construir um material de grande importância que venha estimular outras escolas localizadas em áreas rurais a fazer um trabalho semelhante, a fim de construir um material prático na área de biologia com maior amplitude, o que traz uma compreensão mais profunda e consistente da temática posta mediante atividades pedagógicas e a produção de resultados traduzidos nos relatos de experiências.

Nesta fase onde se aplicou as atividades, pôde-se, do ponto de vista avaliativo, notar que as mesmas ocorreram de forma contínua durante todas as etapas de execução propostas, o que proporcionou o desenvolvimento das capacidades dos alunos com relação à aprendizagem de conceitos, de procedimentos e de atitudes relacionados à temática do projeto.

0 trabalho interdisciplinar enriqueceu nossa abordagem, bem como ajudou a pensar, elaborar, colocar em prática e avaliar as propostas pedagógicas que foram desenvolvidas com o alunado do $1^{\mathrm{o}}$ ano médio da escola em questão. Isto, assim se entende, trouxe uma contribuição importante para entender o ensino da biologia com a ajuda de outras concepções da base curricular.

Conclui-se que todas as atividades propostas, sejam elas específicas da disciplina de Biologia ou até mesmo as que abrangem de maneira interdisciplinar as disciplinas de Língua 
Portuguesa, Matemática e Educação Físicas, se apresentaram como uma importante ferramenta para o processo de ensino e aprendizagem, fazendo com que os alunos desenvolvessem múltiplas habilidades relacionadas ao currículo das disciplinas envolvidas, bem como aos aspectos relacionados a habilidades $\mathrm{e}$ atitudes socioemocionais e fortalecimento das relações interpessoais, como: interação, participação coletiva, cooperação e companheirismo.

\section{Conflito de interesses}

conflito de interesses.

0 autor declara não haver

\section{Referências}

Borges, R. M. R.; Lima, V. M. R. Tendências contemporâneas do ensino de Biologia no Brasil. Revista Electrónica de Enseñanza de las Ciencias, v. 6, n. 1, p. 165-175, 2007.

Britto, N. S.; Silva, T. G. R. Educação do Campo: formação em Ciências da Natureza e o estudo da realidade. Educação \& Realidade, v. 40, n. 3, p. 763-784, 2015.

Freire, P. Carta de Paulo Freire aos professores. Estudos Avançados, v. 15, n. 42, p. 259-268, 2001. https://doi.org/10.1590/ S0103-40142001000200013

Freitas, J. Sustentabilidade: direito ao futuro. Belo Horizonte: Fórum, 2011.

Gomes, T. M.; Farias, A. M. 0 ensino de Ciências na Educação do Campo: uma experiência com temas geradores na escola itinerante do MST. Anais do II Seminário de Pesquisa em Educação do Campo, Londrina, 2011.

Krasilchik, M. Prática de ensino de Biologia. São Paulo: EDUSP, 2004.

Molina, M. Licenciaturas em Educação do Campo e o ensino de Ciências Naturais: desafios à promoção do trabalho docente interdisciplinar. Brasília: MDA, 2014.
Pedrancini, V. D.; Corazza-Nunes, M. J.; Galuch, M. T. B.; Moreira, A. L. O. R.; Ribeiro, A. C. Ensino e aprendizagem de Biologia no Ensino Médio e a apropriação do saber científico e biotecnológico. Revista Electrónica de Enseñanza de las Ciencias, v. 6, n. 2, p. 299-309, 2007.

Pessoa, J. M. Extensões do rural e educação. In: Pessoa, J. M. Educação e ruralidades. Goiânia: Editora UFG, 2007.

Portela, G. L. Abordagens teóricometodológicas: pesquisa quantitativa ou qualitativa eis a questão. Feira de Santana: Universidade Estadual de Feira de Santana, 2004.

Ribeiro, M. Movimento camponês, trabalho e educação: liberdade, autonomia, emancipação: princípios/fins da formação humana. 2. ed. São Paulo: Expressão Popular, 2013.

Santos, B. S. Para além do pensamento abissal: das linhas globais a uma ecologia de saberes. Novos Estudos, n. 79, p. 71-94, 2007.

Seniciato, T.; Cavassan, O. Aulas de campo em ambientes naturais e aprendizagem em ciências: um estudo com alunos do Ensino Fundamental. Ciência \& Educação, v. 1, n. 1, p. 133-147, 2004. https://doi.org/10.1590/ S1516-73132004000100010

Sousa Sobrinho, R. S. A importância do ensino da Biologia para o cotidiano. Fortaleza: Faculdade Integrada da Grande Fortaleza, 2009. (Monografia de graduação). Disponível em: <http://www.nead.fgf. edu.br/novo/material/monografias_biologia /RAIMUNDO_DE_SOUSA_SOBRINHO.pdf $>$.

Acesso em: 10 out. 2019.

Torres, C. M. G.; Carneiro, C. C. B. S. Diretrizes curriculares e identidade docente de professores de Ciências Biológicas. Revista da SBenBio, n. 7, p. 1309-1319, 2014.

Informação da Licença: Este é um artigo Open Access distribuído sob os termos da Licença Creative Commons Attribution, que permite uso irrestrito, distribuição e reprodução em qualquer meio, desde que a obra original seja devidamente citada. 